\title{
A case of 45,X/47,XXX mosaic Turner syndrome: Clinical manifestations and effect of growth hormone treatment
}

Su Hyun $\mathrm{Yoo}^{\oplus}$, Moon Bae Ahn ${ }^{\oplus}$, Shin Hee Kim ${ }^{\oplus}$, Won Kyoung Cho ${ }^{\oplus}$, Min Ho Jung ${ }^{\oplus}$, Byung Kyu Suh ${ }^{\oplus}$, and Kyoungsoon Cho*® Department of Pediatrics, College of Medicine, The Catholic University of Korea, Seoul, Korea

In Turner syndrome (TS), 45,X/47,XXX mosaicism is a rare genotype. Due to its low frequency, the clinical features and prognosis are not clearly known. A 10-year-old girl was diagnosed with 45,X/47,XXX mosaicism TS and presented with short stature. She did not show any other TS phenotypic features, except for short stature, and developed spontaneous puberty and menarche, although she had unilateral ovarian agenesis. She achieved a significant growth improvement following growth hormone treatment. Since 45,X/47,XXX mosaic TS shows different gonadal function from that of classic TS, it is necessary to conduct surveillance for premature ovarian insufficiency.

Key words: Mosaicism, Turner syndrome, Puberty, Growth hormone, Premature ovarian failure, Turner syndrome.

\section{Introduction}

Turner syndrome (TS) is a common chromosomal disorder affecting approximately 1:2,500 live female births and is characterized by partial or complete absence of one $X$ chromosome [1]. About $45 \%$ to $50 \%$ of patients with TS have $45, X$ monosomy, and the remainder have structural chromosome abnormalities or mosaicism [2]. Mosaicism with 46,X,i $(X q) ; 46, X X / 47, X X X$; 46,X,del(Xp); or 46,XX are common mosaic karyotypes in TS [3]. The frequency of patients with $45, X / 47, X X X$ among all patients with TS is estimated to be 1.5\% [4]. However, the exact incidence of $45, X / 47, X X X$ may be slightly higher than $1.5 \%$ because standard cytogenetic analysis may fail to detect mosaic aneuploidy at a very low level or exclude the possibility of tissue-specific mosaicism in patients [5].

Triple-X syndrome $(47, X X X)$ is the most common female chromosomal abnormality, occurring in approximately 1:1,000 female births [6]. The common clinical features include a tall stature, low intellectual ability, and high probability of psychotic problems. Premature ovarian failure and genitourinary tract malformations have been reported. However, pubertal onset, sexual development, and fertility are usually normal.

TS is characterized by a short stature, ovarian failure, congenital malformations of the heart and kidney, and distinctive physical features, including cubitus valgus, a webbed neck, and a wide chest [7]. However, the TS phenotype varies depending on the specific karyotype [5]. The mosaic form of TS tends to manifest with milder phenotypes and improved prognosis.

The aim of this case presentation is to describe the clinical manifestations and report the effect of growth hormone treatment in a Korean patient who was diagnosed with 45,X/47,XXX mosaic TS.

Received: 14 April 2020, Revised: 22 May 2020, Accepted: 24 May 2020, Published: 30 June 2020

*Corresponding author: Kyoungsoon Cho, M.D. (D) https://orcid.org/0000-0002-0212-0992

Department of Pediatrics, College of Medicine, The Catholic University of Korea, 222 Banpo-daero, Seocho-gu, Seoul 06591, Korea.

Tel: +82-2-3779-1389, Fax: +82-2-783-2589, E-mail: soon926@catholic.ac.kr

Conflict of interest: The authors declare that they do not have any conflicts of interest.

(C) This is an open-access article distributed under the terms of the Creative Commons Attribution Non-Commercial License (http://creativecommons.org/licenses/by-nc/4.0/) which permits unrestricted non-commercial use, distribution, and reproduction in any medium, provided the original work is properly cited.

(c) Copyright 2020 by the Korean Society of Medical Genetics and Genomics 


\section{Case}

A 10-year-and-4-month-old girl was brought to a pediatric endocrinology clinic to undergo evaluations for her short stature. The patient's birth weight was $3.3 \mathrm{~kg}$, and she was born via nonsurgical vaginal delivery at full term. She was the first child in the family. She had no other significant medical history and had achieved normal developmental milestones. She was in the fourth grade of elementary school and was performing well in school. Her father's height was $165 \mathrm{~cm}$, and her mother's height was $163.5 \mathrm{~cm}$. There was no familial history of inherited or congenital disease. On physical examination, her height was 125.4 $\mathrm{cm}(-2.68$ of the standard deviation [SD]), and her weight was $28.5 \mathrm{~kg}(-1.27$ of the SD). Clinical features of TS were not observed in the examination. Her Tanner stage was breast I, pubic hair I, and axillary hair I. Her external genitalia appeared normal. She had no cardiac murmur. Her serum laboratory test results revealed $1.28 \mathrm{ng} / \mathrm{dL}$ of free thyroxine (normal range: 0.8 to 1.8 ),
$1.67 \mu \mathrm{lU} / \mathrm{mL}$ of thyroid-stimulating hormone (normal range: 0.5 to 5), $<0.20 \mathrm{mlU} / \mathrm{mL}$ of luteinizing hormone (normal range: 0.02 to 4.7), $2.22 \mathrm{mIU} / \mathrm{mL}$ of follicle-stimulating hormone (normal range: 0 to 10.8), $18.09 \mathrm{pg} / \mathrm{mL}$ of estradiol (normal range: 10 to 24), and $181.73 \mathrm{ng} / \mathrm{mL}$ of insulin-like growth factor-1 (normal range: 85 to 363 ). Her complete blood count and comprehensive metabolic panel were normal. Her bone age was read and interpreted as 10 years according to the standards of Greulich and Pyle [8], which is considered a normal bone age. Cytogenetic analysis of blood lymphocytes revealed a karyotype of TS mosaicism with 45,X(33 cells)/47,XXX(17 cells). Further evaluations of abnormalities related to TS were performed. In pelvic sonography, right ovary was not visualized but small uterus and small left ovary existed. Echocardiography revealed a normal aorta and aortic valve. A renal ultrasound examination showed no urinary tract malformations. An ophthalmologic examination and audiogram showed normal findings. Her mean parental height was $157.5 \mathrm{~cm}$ (-0.53 of the SD) and predictive adult height was

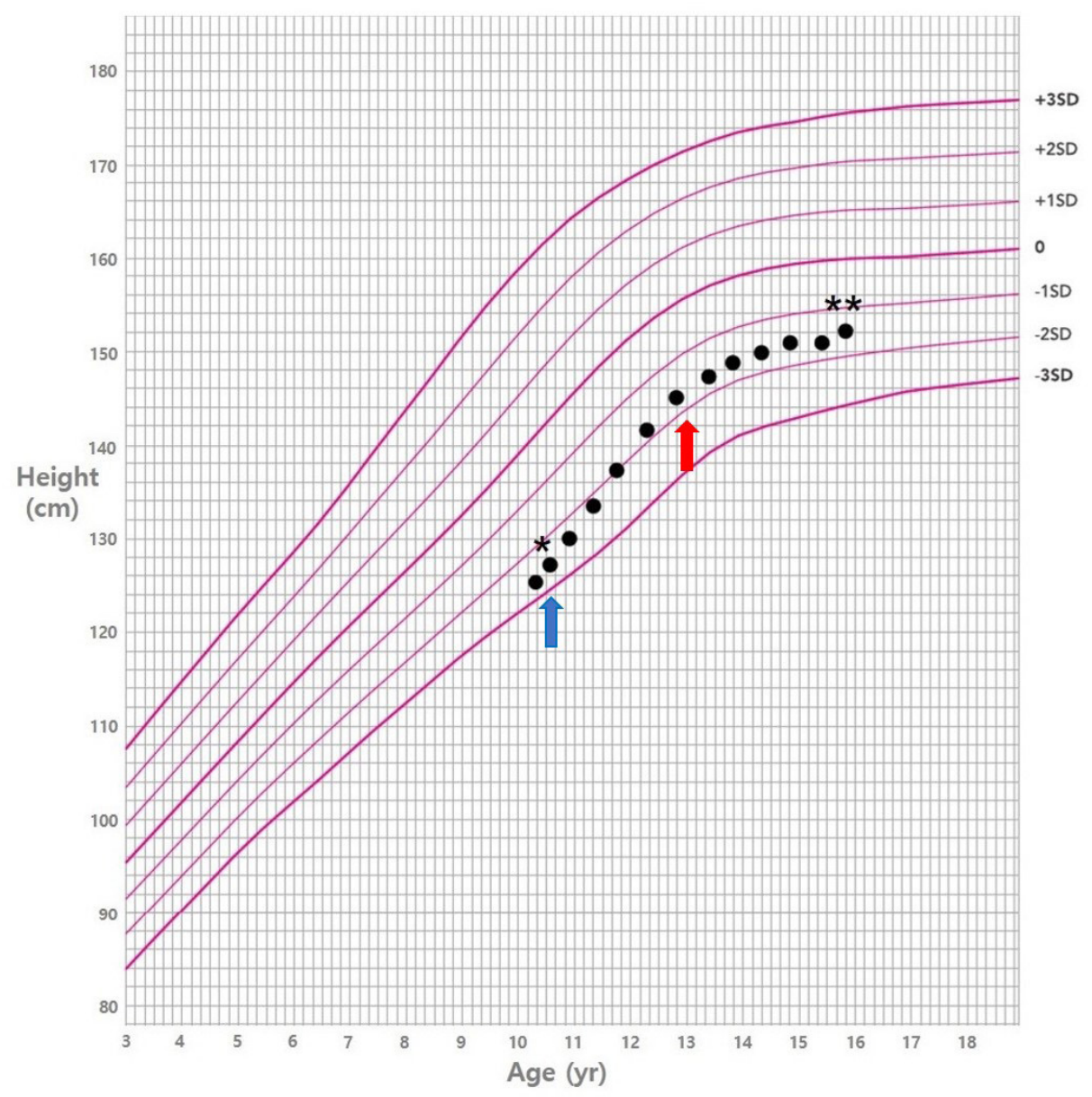

Fig. 1. Growth chart of the patient. Spontaneous breast development (blue arrow) and menarche (red arrow) were observed at 10 years and 7 months and 13 years of age, respectively. *, Initiation of growth hormone $(\mathrm{GH})$ treatment; ${ }^{* \star}$, Withdrawal of $\mathrm{GH}$ treatment; SD, standard deviation. 
$144.3 \mathrm{~cm}(-3.38$ of the SD). To improve her adult height, growth hormone therapy was administered at 10 years and 6 months of age, to which she responded well (Fig. 1). Spontaneous breast development and menarche were observed at 10 years and 7 months and 13 years of age, respectively. At 15 years and 10 months of age, the growth hormone treatment was discontinued. Her near-final adult height was $152.1 \mathrm{~cm}(-1.34$ of the SD). She had regular menstrual cycles, and follow-up pelvic sonography showed a postpubertal uterus and normal left ovary but right ovary was not visualized.

\section{Discussion}

Among patients with TS, 45,X/47,XXX karyotypes are rare and less severe than common TS due to the higher occurrences of puberty, menarche, and fertility and lower occurrence of congenital anomalies $[4,5]$.

TS is an important cause of short stature in girls. The prevalence of a short stature in individuals harboring $45, X / 47, X X X$ is $64.3 \%$, which is much lower than that in $45, X$ monosomy cases (greater than 95\%) [5]. Tang et al. [5] speculated that this may be related to the presence of 47,XXX cell lines because triple- $X$ syndrome often presents with tall stature. However, the prognosis for the final adult height is not guaranteed without growth hormone treatment. In a study by Blair et al. [9] comparing $45, X / 47, X X X$ mosaic TS to common TS [45,X and 45, X/46,Xi(X) (q10)], only 4 of 7 patients harboring $45, X / 47, X X X$ were treated with growth hormones as their heights were -2 of SD or less, and the median/mean height SD before and after treatment showed no statistically significant difference from that in common TS. The near-final adult height of our patient was 152.1 $\mathrm{cm}$, which reached the target height range (between $151 \mathrm{~cm}$ and $164 \mathrm{~cm}$ ) after 5 years of growth hormone treatment. In TS, it is generally known that there is no difference in the response to growth hormone treatment according to the physical abnormality or genotype [10]. However, it is thought that 45,X/47,XXX mosaicism is diagnosed at a relatively old age compared to the age at which common TS is diagnosed, which may negatively affect the effect of growth hormone treatment.

Hypogonadism is one of the most important clinical issues for adolescents and adult TS. Women with 45,X/47,XXX mosaicism are more likely to retain residual ovarian function $[4,5]$. The occurrences of spontaneous puberty and menarche were $88.9 \%$ and $77.1 \%$ respectively [5], much higher than those observed in 45,X monosomy cases (22.4\% and 9.2\%, respectively) [11]. Women with $45, \mathrm{X}$ monosomy rarely become pregnant $(<0.5 \%)$
[12]. However, Tarani et al. [13] reviewed the outcomes of spontaneous pregnancies in 12 women with 45,X/47,XXX karyotypes, which were normal in 16 of 20 pregnancies. However, the risk of premature ovarian insufficiency (POI) in 45, X/47, XXX mosaicism is higher than that in the general population, and ovarian failure is usually observed at around 30 years of age [5]. The ovarian reserve may be monitored by measuring serum anti-Müllerian hormone levels and ovarian antral follicular counts in young patients with mosaic TS with persistent ovarian function, and fertility preservation could be considered before follicles begin to disappear [5]. Our patient also developed spontaneous puberty, menarche, and regular menstruation thus far; however, she has the risk of developing POI. We advised the patient and her parents about possible premature ovarian failure. Through multidisciplinary treatment, regular evaluation of gonadal function will be conducted, and we plan to provide counseling for family planning.

We report here a case of $45, X / 47, X X X$ mosaic TS. The patient presented with a short stature but had no congenital anomalies and developed spontaneous puberty and menarche. After 5 years of growth hormone treatment, her near-final adult height reached the target height range. In our case and according to previous reports, 45,X/47,XXX mosaic TS has milder clinical manifestations than those of classic TS, and patients often retain sexual function until early adulthood. However, the risk of $\mathrm{POI}$ is higher than that in the general population, which needs monitoring of gonadal function and careful counseling for family planning. 45,X/47,XXX mosaic TS is a very rare genotype; thus, the exact clinical course cannot be predicted. More research is needed to provide specific guidelines to ensure a proper approach for growth, pubertal development, and fertility in TS with 45X/47,XXX karyotypes.

\section{References}

1. Stochholm K, Juul S, Juel K, Naeraa RW, Gravholt CH. Prevalence, incidence, diagnostic delay, and mortality in Turner syndrome. J Clin Endocrinol Metab 2006;91:3897-902.

2. Wolff DJ, Van Dyke DL, Powell CM. Laboratory guideline for Turner syndrome. Genet Med 2010;12:52-5.

3. Zhong Q, Layman LC. Genetic considerations in the patient with Turner syndrome--45, X with or without mosaicism. Fertil Steril 2012;98:775-9.

4. Lim HH, Kil HR, Koo SH. Incidence, puberty, and fertility in $45, X / 47$, XXX mosaicism: report of a patient and a literature review. Am J Med Genet A 2017;173:1961-4. 
5. Tang $R$, Lin L, Guo $Z$, Hou $H, Y u$ O. Ovarian reserve evaluation in a woman with $45, X / 47, X X X$ mosaicism: a case report and a review of literature. Mol Genet Genomic Med 2019;7:e00732.

6. Tartaglia NR, Howell S, Sutherland A, Wilson R, Wilson L. A review of trisomy X (47,XXX). Orphanet J Rare Dis 2010;5:8.

7. Turner HH. A syndrome of infantilism, congenital webbed neck, and cubitus valgus. Endocrinology 1938;23:566-74.

8. Greulich WW, Pyle SI. Radiographic atlas of skeletal development of the hand and wrist. 2nd ed. Stanford University Press, 1959.

9. Blair J, Tolmie J, Hollman AS, Donaldson MD. Phenotype, ovarian function, and growth in patients with 45, X/47, XXX Turner mosaicism: implications for prenatal counseling and estrogen therapy at puberty. J Pediatr 2001;139:724-8.
10. Haeusler G, Schmitt K, Blümel P, Plöchl E, Waldhör T, Frisch H. Growth hormone in combination with anabolic steroids in patients with Turner syndrome: effect on bone maturation and final height. Acta Paediatr 1996;85:1408-14.

11. Pasquino AM, Passeri F, Pucarelli I, Segni M, Municchi G. Spontaneous pubertal development in Turner's syndrome. Italian Study Group for Turner's Syndrome. J Clin Endocrinol Metab 1997;82:1810-3.

12. Birkebaek NH, Crüger D, Hansen J, Nielsen J, Bruun-Petersen G. Fertility and pregnancy outcome in Danish women with Turner syndrome. Clin Genet 2002;61:35-9.

13. Tarani L, Lampariello S, Raguso G, Colloridi F, Pucarelli I, Pasquino AM, et al. Pregnancy in patients with Turner's syndrome: six new cases and review of literature. Gynecol Endocrinol 1998;12:83-7. 